\title{
Is ramucirumab and paclitaxel therapy beneficial for second-line treatment of metastatic gastric or junctional adenocarcinoma for patients with ascites? Analysis of RAINBOW phase 3 trial data
}

This article was published in the following Dove Medical Press journal: Cancer Management and Research

\author{
Kei Muro' \\ Min-Hua Jen ${ }^{2}$ \\ Rebecca Cheng ${ }^{3}$ \\ 'Department of Clinical Oncology, \\ Outpatient Treatment Center, Aichi \\ Cancer Center Hospital, Nagoya, \\ Japan; ${ }^{2}$ Eli Lilly and Company Ltd, \\ Windlesham, Surrey, UK; ${ }^{3}$ Eli Lilly and \\ Company, Taipei, Taiwan
}

\begin{abstract}
Purpose: Second-line treatment with ramucirumab-paclitaxel has demonstrated statistically significant and clinically meaningful survival outcomes compared to paclitaxel-alone in patients with advanced gastric cancer $(\mathrm{HR}=0.807,95 \% \mathrm{CI} 0.678-0.962 ; P=0.017)$. Post hoc, exploratory analyses of RAINBOW patient data were performed to examine whether ascites impacted the efficacy and safety of ramucirumab-paclitaxel.
\end{abstract}

Patients and methods: Patients were placed in with- or without-ascites subgroups based on baseline information collected on case report forms. The Kaplan-Meier method was used to estimate median progression-free survival (PFS) and overall survival (OS) of the ascites subgroups. HR and $95 \%$ CI were calculated using the Cox proportional hazards model. Survival distributions within the two arms in each ascites subgroup were compared using the log-rank test. Results: There were $36 \%$ of RAINBOW trial patients $(237 / 665)$ that had ascites at baseline (with-ascites subgroup); 64\% of patients (428/665) had no baseline ascites (without-ascites subgroup). Most baseline characteristics were balanced. The with-ascites subgroup had a higher percentage of patients with peritoneal metastases (91\% vs $23 \%$ ) as expected. Overall survival for the with-ascites subgroup was worse than for the without-ascites subgroup (median OS for placebo-treated patients: 5.2 vs 8.5 months, respectively). However, OS treatment effects did not seem to differ significantly among patients with ascites (OS stratified HR $=0.864$, 95\% CI $=0.644-1.161 ; P=0.3362$ ) vs those without ascites (OS stratified HR=0.745, 95\% $\mathrm{CI}=0.593-0.936 ; P=0.0115)$. Similar results were observed for PFS. Ramucirumab treatment was associated with a greater incidence of all-grade vomiting for the with-ascites subgroup vs the without-ascites subgroup (ramucirumab arm: $39.2 \%$ vs $18.8 \%$; placebo arm: $23.3 \%$ vs $19.5 \%$, respectively). The incidence of adverse events of special interest was not elevated among the ramucirumab-treated ascites subgroup over the without-ascites subgroup.

Conclusion: The benefit/risk profile of ramucirumab-paclitaxel remains favorable in patients with ascites and is consistent with the findings of the RAINBOW trial.

Keywords: gastric cancer, GEJ, peritoneal metastases, efficacy, safety

\section{Introduction}

Gastric cancer is the fifth most frequently diagnosed cancer (1.03 million cases projected in 2018) but the third highest cause of cancer-related death due to frequent late stage detection and concomitant high mortality ( $76 \%$ mortality rate). ${ }^{1,2}$ First-line treatment of advanced or metastatic gastric or gastroesophageal junction (GEJ) cancer 
involves platinum and fluoropyrimidine chemotherapy, with a third agent sometimes added based on human epidermal growth factor receptor 2 status. ${ }^{3-5}$ Upon disease progression after the front line therapy, second-line chemotherapy with irinotecan or a taxane yields a survival benefit over best supportive care. Recently, the phase 3 REGARD trial identified a new option for second-line treatment- ramucirumab, a human immunoglobulin G1 monoclonal antibody against the vascular endothelial growth factor receptor-2 (VEGFR-2). ${ }^{6}$ The subsequent phase 3 RAINBOW trial revealed the addition of ramucirumab to second-line paclitaxel significantly extended second-line overall survival (OS; median 9.6 vs 7.4 months; hazard ratio $[\mathrm{HR}]=0.807 ; P=0.017$ ) and progressionfree survival (PFS; median 4.4 vs 2.9 months; HR=0.635; $P<0.0001)$ over placebo-paclitaxel. ${ }^{7}$

Malignancy-related ascites is a frequent complication of advanced gastric cancer. It is thought to develop in conjunction with peritoneal tumors, in part due to the elevated concentration of VEGF in the peritoneal fluid and the resultant increased peritoneal capillary permeability. ${ }^{8}$ Malignancy-occluded lymphatic vessels or portal hypertension resulting from hepatic metastases may also contribute to ascites formation. Critical complications such as infection, ileus, peritonitis, and hydronephrosis can follow ascites. Due to these potential complications and the numerous ascitesassociated symptoms, clinicians proceed cautiously with second-line treatments. To assess the efficacy and safety of ramucirumab-paclitaxel second-line treatment for patients with ascites, post hoc, exploratory analyses of RAINBOW patient data were performed.

\section{Methods}

\section{Study design}

Details of the RAINBOW global, randomized, doubleblind, placebo-controlled phase 3 trial (ClinicalTrials. gov NCT01170663) have been reported. ${ }^{7}$ In brief, eligible patients met the following criteria: metastatic or nonresectable, locally advanced gastric or GEJ adenocarcinoma; disease progression during or within 4 months of the last dose of first-line platinum/fluoropyrimidine (with or without anthracycline); Eastern Cooperative Oncology Group (ECOG) performance status score of 0 or 1 ; and measurable or nonmeasurable evaluable disease as defined by Response Evaluation Criteria in Solid Tumors version 1.1. Patients were randomized $(1: 1)$ with stratification by time to progression after first dose of first-line therapy ( $<6$ months vs $\geq 6$ months), disease measurability (yes vs no), and region. Patients were treated either with intravenous ramucirumab
$(8 \mathrm{mg} / \mathrm{kg})$ or placebo on days 1 and 15 , and paclitaxel (80 $\mathrm{mg} / \mathrm{m}^{2}$ ) on days 1,8 , and 15 of a 28 -day cycle. Treatment was discontinued upon disease progression, unacceptable toxicity, or withdrawal of consent.

The RAINBOW trial followed the guiding principles of the Declaration of Helsinki and the Good Clinical Practice Guidelines of the International Conference on Harmonization. The institutional review board or independent ethics committee of each investigative site approved the trial (listing supplied in Supplementary materials), and all patients provided written informed consent.

\section{Statistical methods}

Patients were designated as with-ascites or without-ascites subgroup based on investigator report of ascites at baseline as recorded on the patient case report form in response to a single question. Information on the volume of ascites and the diagnostic method was not collected. The Kaplan-Meier method was used to estimate median PFS and OS of the ascites subgroups. The log-rank test was used to compare the survival distributions within the two arms in each ascites subgroup. HR and 95\% confidence interval (CI) were calculated using the Cox proportional hazards model.

\section{Results}

Among the 665 patients participating in the RAINBOW trial, $237(36 \%)$ had ascites at baseline and were included in the "with-ascites" subgroup; the remaining 428 patients (64\%) were classified as the "without-ascites" subgroup. Baseline patient and tumor characteristics were generally balanced between the treatment arms within the ascites subgroups (Table 1). As expected, the subgroup with ascites had a much higher percentage of patients with peritoneal metastases $(91 \%$ vs $23 \%$ ). In addition, the ascites subgroup, vs the subgroup without ascites, had a higher percentage of women $(44 \%$ vs $21 \%$ ), patients with primary tumor of gastric cancer (vs GEJ) (94\% vs 71\%), and patients with diffuse histological subtype (53\% vs $29 \%)$.

\section{Efficacy}

Overall survival for the with-ascites subgroup was worse than that for the without-ascites subgroup. In the ascites subgroup, placebo-treated patients exhibited a median OS of 5.2 months (Figure 1A), while placebo-treated patients without ascites exhibited a median OS of 8.5 months (Figure 1B). In contrast, median PFS was similar for placebo-treated patients in both the with-ascites and without-ascites subgroups (2.8 and 2.9 months, respectively) (Figure 1C, 1D). 
Table I Summary of patient and disease characteristics in patient subgroups with and without ascites

\begin{tabular}{|c|c|c|c|c|}
\hline & \multicolumn{2}{|c|}{ Patients with ascites } & \multicolumn{2}{|c|}{ Patients without ascites } \\
\hline & $\begin{array}{l}\text { Ramucirumab + } \\
\text { paclitaxel } \\
(\mathrm{N}=130) \text { n (\%) }\end{array}$ & $\begin{array}{l}\text { Placebo+ } \\
\text { paclitaxel } \\
(\mathrm{N}=107) \text { n (\%) }\end{array}$ & $\begin{array}{l}\text { Ramucirumab + } \\
\text { paclitaxel } \\
(\mathrm{N}=\mathbf{2 0 0}) \mathrm{n}(\%)\end{array}$ & $\begin{array}{l}\text { Placebo+ } \\
\text { paclitaxel } \\
(\mathbf{N}=\mathbf{2 2 8}) \text { n (\%) }\end{array}$ \\
\hline Age, median (range) (years) & $59(25-79)$ & $60(24-8 I)$ & $63(29-83)$ & $62(28-84)$ \\
\hline \multicolumn{5}{|l|}{ Sex } \\
\hline Male & $71(54.6)$ & $62(57.9)$ & $158(79.0)$ & I8I (79.4) \\
\hline Female & $59(45.4)$ & $45(42.1)$ & $42(21.0)$ & $47(20.6)$ \\
\hline \multicolumn{5}{|l|}{ ECOG PS } \\
\hline 0 & $43(33.1)$ & $39(36.4)$ & $74(37.0)$ & $105(46.1)$ \\
\hline I & $87(66.9)$ & $68(63.6)$ & $126(63.0)$ & $123(53.9)$ \\
\hline \multicolumn{5}{|l|}{ Weight loss in the previous 3 months } \\
\hline$\geq 10 \%$ & $25(19.2)$ & $20(18.7)$ & $28(14.0)$ & $27(11.8)$ \\
\hline$<10 \%$ & $105(80.8)$ & $87(81.3)$ & $172(86.0)$ & $199(87.3)$ \\
\hline \multicolumn{5}{|l|}{ Primary tumor location } \\
\hline Gastric & $122(93.8)$ & $101(94.4)$ & | $42(7 \mid .0)$ & $163(7 \mid .5)$ \\
\hline GEJ & $8(6.2)$ & $6(5.6)$ & $58(29.0)$ & $65(28.5)$ \\
\hline \multicolumn{5}{|l|}{ Histological subtype } \\
\hline Intestinal & $42(32.3)$ & $25(23.4)$ & $103(5 \mid .5)$ & $110(48.2)$ \\
\hline Diffuse & $66(50.8)$ & $59(55.1)$ & $49(24.5)$ & $74(32.5)$ \\
\hline Mixed & $7(5.4)$ & $6(5.6)$ & $14(7.0)$ & $8(3.5)$ \\
\hline Unknown & $15(11.5)$ & $17(15.9)$ & $34(17.0)$ & $36(15.8)$ \\
\hline Primary tumor present & $95(73.1)$ & $74(69.2)$ & $114(57.0)$ & $135(59.2)$ \\
\hline \multicolumn{5}{|l|}{ Number of metastatic sites } \\
\hline $0-2$ & $75(57.7)$ & $71(66.4)$ & $134(67.0)$ & $161(70.6)$ \\
\hline$\geq 3$ & $55(42.3)$ & $36(33.6)$ & $66(33.0)$ & $67(29.4)$ \\
\hline Peritoneal metastases & $116(89.2)$ & $100(93.5)$ & $47(23.5)$ & $52(22.8)$ \\
\hline Measureable disease & $79(60.8)$ & $63(58.9)$ & $177(88.5)$ & $202(88.6)$ \\
\hline \multicolumn{5}{|l|}{ Time to progressive disease on first-line therapy } \\
\hline$<6$ months & $97(74.6)$ & $65(60.7)$ & III (55.5) & $135(59.2)$ \\
\hline$\geq 6$ months & $33(25.4)$ & $42(39.3)$ & $89(44.5)$ & $92(40.4)$ \\
\hline Missing & 0 & 0 & 0 & $\mathrm{I}(0.4)$ \\
\hline \multicolumn{5}{|l|}{ Prior first-line therapy } \\
\hline Doublet: platinum and fluoropyrimidine & $98(75.4)$ & $80(74.8)$ & $155(77.5)$ & $166(72.8)$ \\
\hline $\begin{array}{l}\text { Triplet: platinum and fluoropyrimidine with } \\
\text { anthracycline }\end{array}$ & $32(24.6)$ & $26(24.3)$ & $44(22.0)$ & $61(26.8)$ \\
\hline
\end{tabular}

Abbreviations: GEJ, gastro-esophageal junction; ECOG PS, Eastern Cooperative Oncology Group performance status.

Although the study was not powered for subgroup analysis, Kaplan-Meier plots were used to examine the treatment effect in both ascites subgroups. As shown in Figure 1, the ramucirumab arm exhibited prolonged survival $(\mathrm{HR}<1)$ for both ascites subgroups: the with-ascites subgroup (stratified $\mathrm{HR}=0.864,95 \% \mathrm{CI}=0.644-1.161 ; P=0.3362)$ and the without-ascites subgroup ( $\mathrm{HR}=0.745,95 \% \mathrm{CI}=0.593-0.936$; $P=0.0115)$. A similar trend was observed for PFS, with a stratified HR of 0.785 ( $95 \% \mathrm{CI}=0.583-1.056 ; P=0.1123$ ) for the with-ascites subgroup and $0.543(95 \% \mathrm{CI}=0.438-0.673$; $P<0.0001)$ for the without-ascites subgroup. Table 2 summarizes the results of the ascites subgroups and compares them with those from the full intent-to-treat population from the RAINBOW trial. A separate analysis examined the ascites subgroups within the subpopulation of patients with peritoneal metastases and found similar results (Table S1).

\section{Safety}

Among patients with ascites, median duration of therapy was 14 weeks (interquartile range [IQR] 8-24) for the ramucirumab arm and 12 weeks (IQR 6-20) for placebo. By comparison, the median duration of therapy for all study patients on the ramucirumab arm was 18 weeks (IQR 10-31). The median relative dose intensity for ramucirumab/placebo was $99 \%$ among patients with ascites.

Ramucirumab treatment was associated with a greater incidence of vomiting for the patients with-ascites subgroup vs ramucirumab-treated patients without ascites (any grade 


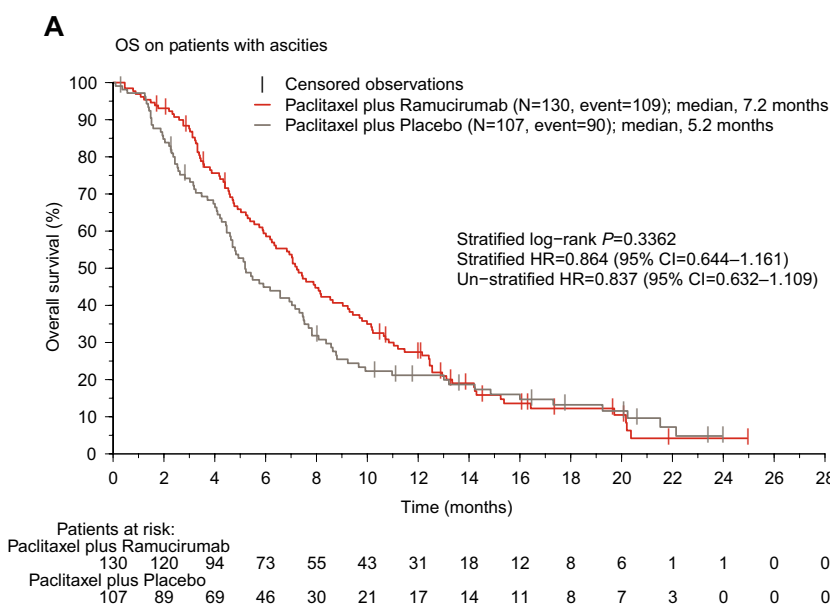

C

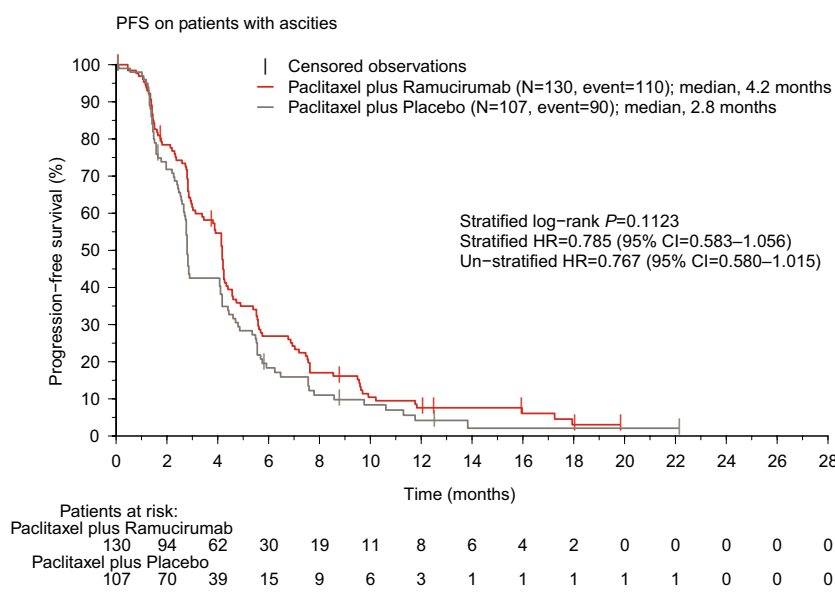

B

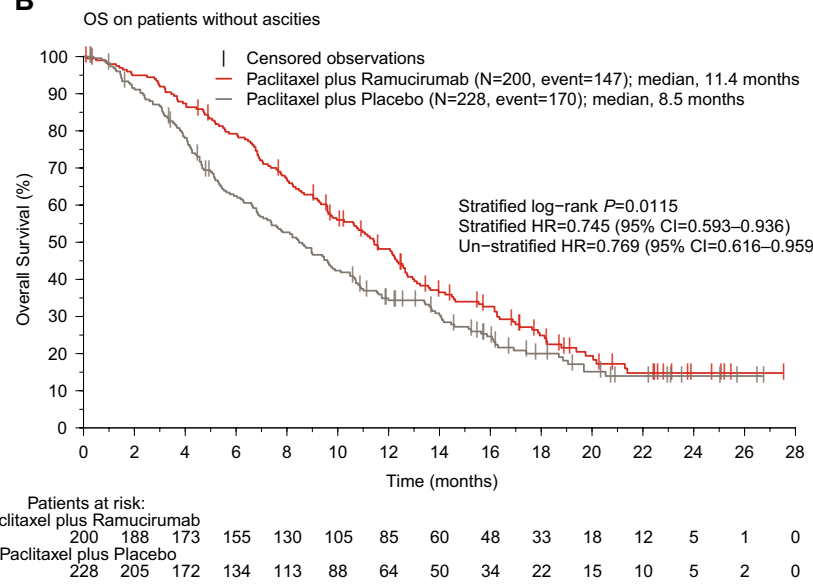

D

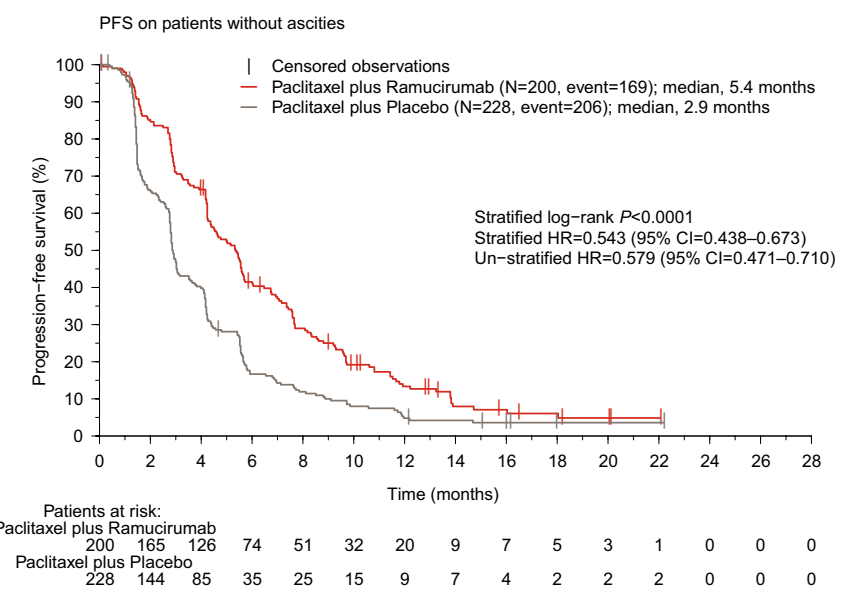

Figure I Kaplan-Meier curves of OS and PFS in subgroups with and without ascites.

Notes: OS (A, B) and PFS (C, D) were calculated using Kaplan-Meier plots of subgroups of patients with ascites (A, C) and without ascites (B, D). Treatment HRs and 95\% confidence intervals were estimated from a stratified Cox model adjusted for covariates (stratification factors).

Abbreviations: OS, overall survival; PFS, progression-free survival.

vomiting $39.2 \%$ vs $18.8 \%$, respectively; grade $3-4$ vomiting $4.6 \%$ vs $2.0 \%$, respectively) (Table 3). Independent of treatment, patients with ascites experienced a greater incidence of low-grade hypoalbuminemia. The with-ascites subgroup receiving ramucirumab exhibited a higher incidence of any grade leukopenia and any grade anemia as compared to the without-ascites subgroup. Adverse events of special interest were not elevated among the ramucirumab-treated ascites subgroup over the subgroup of ramucirumab-treated patients without ascites. The incidence of grade $\geq 3$ GI perforation was $0.8 \%$ for ramucirumab-treated patients in the withascites subgroup and $1.5 \%$ in the without-ascites subgroup. Likewise, severe (grade $\geq 3$ ) arterial thromboembolic events were not elevated among ramucirumab-treated patients with ascites $(0 \%)$ vs ramucirumab-treated patients without ascites $(1.5 \%)$. The incidence of grade $\geq 3$ venous thromboembolic events was also similar among ramucirumab-treated patients in both the with- and without-ascites subgroups (3.8\% and $1.5 \%$, respectively). The incidence of all grade and grade $\geq 3$ hypertension was lower among patients with ascites compared to patients without ascites for both ramucirumabtreated and placebo-treated subgroups (Table 3).

\section{Discussion}

Patients with advanced gastric/GEJ cancer may suffer from malignancy-related ascites, a condition associated with a poorer prognosis - shorter OS and inferior quality of life. ${ }^{8,9}$ Standard clinical management of ascites may lead to temporary palliation of symptoms but is unlikely to improve survival. ${ }^{10}$ Ramucirumab in combination with paclitaxel has demonstrated statistically significant and clinically meaningful survival outcomes compared to paclitaxel alone in patients receiving second-line treatment for advanced gastric cancer. The post hoc, exploratory analyses reported here examined 
Table 2 Summary of efficacy data for intent-to-treat population and ascites subgroups

\begin{tabular}{|c|c|c|c|c|c|c|}
\hline & \multicolumn{2}{|l|}{ ITT population } & \multicolumn{2}{|c|}{$\begin{array}{l}\text { ITT population with-ascites } \\
\text { subgroup }\end{array}$} & \multicolumn{2}{|c|}{$\begin{array}{l}\text { ITT population without-ascites } \\
\text { subgroup }\end{array}$} \\
\hline & $\begin{array}{l}\text { Ramucirumab + } \\
\text { paclitaxel } \\
(\mathbf{N}=330)\end{array}$ & $\begin{array}{l}\text { Placebo+ } \\
\text { paclitaxel } \\
(\mathbf{N}=335)\end{array}$ & $\begin{array}{l}\text { Ramucirumab + } \\
\text { paclitaxel } \\
(\mathbf{N}=130)\end{array}$ & $\begin{array}{l}\text { Placebo+ } \\
\text { paclitaxel } \\
(\mathrm{N}=107)\end{array}$ & $\begin{array}{l}\text { Ramucirumab + } \\
\text { paclitaxel } \\
(\mathbf{N}=\mathbf{2 0 0})\end{array}$ & $\begin{array}{l}\text { Placebo+ } \\
\text { paclitaxel } \\
(\mathbf{N}=228)\end{array}$ \\
\hline $\begin{array}{l}\text { Overall survival } \\
\text { Median (months) }\end{array}$ & 9.6 & 7.4 & 7.2 & 5.2 & 11.4 & 8.5 \\
\hline Stratified log-rank $P$ & \multicolumn{2}{|c|}{0.017} & \multicolumn{2}{|c|}{0.3362} & \multicolumn{2}{|c|}{0.0115} \\
\hline Stratified HR $(95 \% \mathrm{Cl})$ & \multicolumn{2}{|c|}{$0.807(0.678-0.962)$} & \multicolumn{2}{|c|}{$0.864(0.644-1.161)$} & \multicolumn{2}{|c|}{$0.745(0.593-0.936)$} \\
\hline $\begin{array}{l}\text { Progression-free survival } \\
\text { Median (months) }\end{array}$ & 4.4 & 2.9 & 4.2 & 2.8 & 5.4 & 2.9 \\
\hline Stratified log-rank $P$ & \multicolumn{2}{|c|}{$<0.0001$} & \multicolumn{2}{|c|}{0.1123} & \multicolumn{2}{|c|}{$<0.0001$} \\
\hline Stratified HR $(95 \% \mathrm{Cl})$ & \multicolumn{2}{|c|}{$0.635(0.536-0.752)$} & \multicolumn{2}{|c|}{$0.785(0.583-1.056)$} & \multicolumn{2}{|c|}{$0.543(0.438-0.673)$} \\
\hline
\end{tabular}

Abbreviation: ITT, intent-to-treat.

the safety and efficacy of second-line ramucirumab-paclitaxel for treatment of advanced gastric cancer in patients with and without ascites.

The RAINBOW with-ascites subgroup was similar to the without-ascites subgroup for most baseline patient and disease characteristics. Peritoneal metastases were higher among patients with ascites, as expected. There was also a higher incidence of female patients and diffuse histology in the with-ascites group, as another report has observed. ${ }^{11}$ Comparison of RAINBOW patient subgroups revealed a favorable ramucirumab treatment trend among patients with and without ascites (OS and PFS HR <1), compared to placebo. This trend was duplicated in the population of patients with peritoneal metastases. Assessment of adverse events associated with ramucirumab-treatment of patients with and without ascites did not identify any new safety concerns associated with treatment.

As other studies have observed, gastric cancer patients with ascites have a poorer prognosis than those without ascites. ${ }^{8,9}$ Indeed, as already reported for the RAINBOW trial, a stepwise Cox model identified absence of ascites as an independent predictor for improved survival. ${ }^{7}$ Comparing placebo-treated subgroups, those with ascites had a median OS of 5.2 as compared with 8.5 months for those without ascites. Despite the poor prognosis, our analyses suggest that combining ramucirumab with paclitaxel may assist in prolonging survival even for patients with ascites (increased median OS by 2.0 months vs 2.9 months for patients without ascites).

In addition to the known limitations of post hoc, exploratory analyses, the RAINBOW trial ascites analyses were limited by the absence of patient data on the degree of ascites and lack of periodic monitoring of ascites changes.
Furthermore, these analyses were likely limited by the potential exclusion of some patients with a large volume of ascites since these patients frequently have poor performance status and thus were ineligible for enrolment. ${ }^{7}$ Recent studies have reported on how the extent of ascites impacts treatment outcome. ${ }^{8,9,11,12}$ One retrospective evaluation of data from gastric cancer patients treated with ramucirumab-paclitaxel found that patients with massive ascites had shorter OS and PFS than patients with small to moderate ascites, although the ramucirumab-paclitaxel treatment was tolerated in all patients. ${ }^{11}$ Another retrospective study observed a subgroup with high ascites level had lower median PFS and OS values than the patient subgroup with a low ascites level, although both subgroups responded to ramucirumab. ${ }^{12}$ Future investigations that prospectively plan to study outcomes for patients with ascites should include routine measurement of ascites volume throughout the study.

\section{Conclusion}

Patients with advanced gastric cancer and malignancy-related ascites have a poor prognosis, potentially critical complications, and a myriad of debilitating symptoms. The benefit/ risk profile of ramucirumab-paclitaxel compared to that of paclitaxel appears to be maintained in patients with ascites. This is consistent with the findings in the randomized intentto-treat population in the RAINBOW trial, which inform treatment recommendations in all major guidelines. ${ }^{3-5}$

\section{Abbreviations}

ECOG, Eastern Cooperative Oncology Group; GEJ, gastroesophageal junction; PFS, progression-free survival; VEGFR-2, vascular endothelial growth factor receptor-2. 
Table 3 Treatment-emergent adverse events regardless of causality in patient subgroups with and without ascites

\begin{tabular}{|c|c|c|c|c|c|c|c|c|}
\hline & \multicolumn{4}{|c|}{ Patients with ascites } & \multicolumn{4}{|c|}{ Patients without ascites } \\
\hline & \multicolumn{2}{|c|}{$\begin{array}{l}\text { Ramucirumab + } \\
\text { Paclitaxel }(\mathrm{N}=130)\end{array}$} & \multicolumn{2}{|c|}{$\begin{array}{l}\text { Placebo + Paclitaxel } \\
(\mathrm{N}=103)\end{array}$} & \multicolumn{2}{|c|}{$\begin{array}{l}\text { Ramucirumab + } \\
\text { Paclitaxel }(\mathrm{N}=197)\end{array}$} & \multicolumn{2}{|c|}{$\begin{array}{l}\text { Placebo + Paclitaxel } \\
(\mathbf{N}=\mathbf{2 2 6})\end{array}$} \\
\hline & $\begin{array}{l}\text { Any grade } \\
\text { n (\%) }\end{array}$ & $\begin{array}{l}\text { Grade } \geq 3 \\
n(\%)\end{array}$ & $\begin{array}{l}\text { Any grade } \\
\text { n (\%) }\end{array}$ & $\begin{array}{l}\text { Grade } \geq 3 \\
n(\%)\end{array}$ & $\begin{array}{l}\text { Any grade } \\
\text { n (\%) }\end{array}$ & $\begin{array}{l}\text { Grade } \geq 3 \\
\text { n (\%) }\end{array}$ & $\begin{array}{l}\text { Any grade } \\
\text { n (\%) }\end{array}$ & $\begin{array}{l}\text { Grade } \geq 3 \\
\text { n (\%) }\end{array}$ \\
\hline \multicolumn{9}{|c|}{ Any grade TEAE in $\geq 10 \%$ of patients with ascites in ramucirumab-paclitaxel arm } \\
\hline Fatigue $^{\mathrm{a}}$ & $69(53.1)$ & $16(12.3)$ & $46(44.7)$ & $6(5.8)$ & $117(59.4)$ & $23(11.7)$ & $98(43.4)$ & $12(5.3)$ \\
\hline Neuropathy & $55(42.3)$ & $7(5.4)$ & $34(33.0)$ & $4(3.9)$ & $95(48.2)$ & $20(10.2)$ & $85(37.6)$ & II (4.9) \\
\hline Nausea & $52(40.0)$ & $4(3.1)$ & $37(35.9)$ & $3(2.9)$ & $63(32.0)$ & $2(1.0)$ & $71(31.4)$ & $5(2.2)$ \\
\hline Decreased appetite & $52(40.0)$ & $6(4.6)$ & $38(36.9)$ & $8(7.8)$ & $79(40.1)$ & $4(2.0)$ & $67(29.6)$ & $5(2.2)$ \\
\hline Vomiting & $51(39.2)$ & $6(4.6)$ & $24(23.3)$ & $8(7.8)$ & $37(18.8)$ & $4(2.0)$ & 44 (19.5) & $4(1.8)$ \\
\hline Abdominal pain ${ }^{\mathrm{a}}$ & $51(39.2)$ & $8(6.2)$ & $29(28.2)$ & $3(2.9)$ & $67(34.0)$ & $12(6.1)$ & $69(30.5)$ & $8(3.5)$ \\
\hline Diarrhea & $46(35.4)$ & $4(3.1)$ & $23(22.3)$ & $I(1.0)$ & $60(30.5)$ & $8(4.1)$ & $53(23.5)$ & $4(1.8)$ \\
\hline Alopecia & $37(28.5)$ & 0 & $36(35.0)$ & 0 & $70(35.5)$ & 0 & $91(40.3)$ & $\mathrm{I}(0.4)$ \\
\hline Peripheral edema & $30(23.1)$ & $4(3.1)$ & $20(19.4)$ & $2(1.9)$ & $52(26.4)$ & $\mathrm{I}(0.5)$ & $25(11.1)$ & 0 \\
\hline Pyrexia & $26(20.0)$ & $2(1.5)$ & $16(15.5)$ & 0 & $33(16.8)$ & $\mathrm{I}(0.5)$ & $21(9.3)$ & $\mathrm{I}(0.4)$ \\
\hline Constipation & $25(19.2)$ & 0 & $23(22.3)$ & $\mathrm{I}(\mathrm{I} .0)$ & $45(22.8)$ & 0 & $48(21.2)$ & $\mathrm{I}(0.4)$ \\
\hline Stomatitis & $24(18.5)$ & $I(0.8)$ & $7(6.8)$ & $I(1.0)$ & $40(20.3)$ & $\mathrm{I}(0.5)$ & $17(7.5)$ & $\mathrm{I}(0.4)$ \\
\hline Weight decreased & $22(16.9)$ & $3(2.3)$ & $20(19.4)$ & $3(2.9)$ & $23(11.7)$ & $3(1.5)$ & $29(12.8)$ & $\mathrm{I}(0.4)$ \\
\hline Dyspnea & $20(15.4)$ & $4(3.1)$ & $8(7.8)$ & 0 & $22(11.2)$ & $4(2.0)$ & $23(10.2)$ & $2(0.9)$ \\
\hline Hypoalbuminemia $^{a}$ & $20(15.4)$ & $2(1.5)$ & $\mathrm{II}(10.7)$ & $2(1.9)$ & $16(8.1)$ & $2(1.0)$ & $5(2.2)$ & I (0.4) \\
\hline Rash $^{\mathrm{a}}$ & $17(13.1)$ & 0 & $7(6.8)$ & 0 & $25(12.7)$ & 0 & $24(10.6)$ & 0 \\
\hline Back pain & $15(11.5)$ & 0 & $8(7.8)$ & 0 & $24(12.2)$ & $4(2.0)$ & $32(14.2)$ & $5(2.2)$ \\
\hline \multicolumn{9}{|c|}{ Hematologic adverse events in $\geq 10 \%$ of patients in ramucirumab-paclitaxel ${ }^{a}$} \\
\hline Neutropenia & $75(57.7)$ & $50(38.5)$ & $36(35.0)$ & $23(22.3)$ & $103(52.3)$ & $83(42.1)$ & $66(29.2)$ & $39(17.3)$ \\
\hline Leukopenia & $53(40.8)$ & $24(18.5)$ & $24(23.3)$ & II (I0.7) & $58(29.4)$ & $33(16.8)$ & 45 (19.9) & II (4.9) \\
\hline Anemia & $52(40.0)$ & $16(12.3)$ & $38(36.9)$ & $10(9.7)$ & $62(31.5)$ & $14(7.1)$ & $81(35.8)$ & $24(10.6)$ \\
\hline Thrombocytopenia & $17(13.1)$ & $4(3.1)$ & $6(5.8)$ & $2(1.9)$ & $26(13.2)$ & $\mathrm{I}(0.5)$ & $14(6.2)$ & $4(1.8)$ \\
\hline \multicolumn{9}{|c|}{ Adverse events of special interest ${ }^{a}$} \\
\hline Bleeding/hemorrhage & $48(36.9)$ & $6(4.6)$ & $19(18.4)$ & $3(2.9)$ & $89(45.2)$ & $8(4.1)$ & $40(17.7)$ & $5(2.2)$ \\
\hline Hypertension & $24(18.5)$ & $12(9.2)$ & $2(1.9)$ & $I(1.0)$ & $58(29.4)$ & $36(18.3)$ & $17(7.5)$ & $8(3.5)$ \\
\hline Proteinuria & $21(16.2)$ & $I(0.8)$ & $8(7.8)$ & 0 & $34(17.3)$ & $3(1.5)$ & $12(5.3)$ & 0 \\
\hline Gastrointestinal hemorrhage & $13(10.0)$ & $6(4.6)$ & $5(4.9)$ & 0 & $20(10.2)$ & $6(3.0)$ & $15(6.6)$ & $5(2.2)$ \\
\hline Renal failure & $8(6.2)$ & $5(3.8)$ & $4(3.9)$ & $\mathrm{I}(\mathrm{I} .0)$ & $14(7.1)$ & $\mathrm{I}(0.5)$ & $10(4.4)$ & $2(0.9)$ \\
\hline Infusion-related reaction & $8(6.2)$ & $I(0.8)$ & $3(2.9)$ & 0 & II (5.6) & $\mathrm{I}(0.5)$ & $9(4.0)$ & 0 \\
\hline Venous thromboembolic & $6(4.6)$ & $5(3.8)$ & $8(7.8)$ & $6(5.8)$ & $7(3.6)$ & $3(1.5)$ & $10(4.4)$ & $5(2.2)$ \\
\hline Congestive heart failure & $3(2.3)$ & $\mathrm{I}(0.8)$ & $3(2.9)$ & $I(1.0)$ & $5(2.5)$ & I (0.5) & $\mathrm{I}(0.4)$ & I (0.4) \\
\hline Gastrointestinal perforation & $\mathrm{I}(0.8)$ & $\mathrm{I}(0.8)$ & 0 & 0 & $3(1.5)$ & $3(1.5)$ & $\mathrm{I}(0.4)$ & 0 \\
\hline Arterial thromboembolic & 0 & 0 & $2(1.9)$ & $\mathrm{I}(\mathrm{I} .0)$ & $6(3.0)$ & $3(1.5)$ & $3(1.3)$ & $2(0.9)$ \\
\hline
\end{tabular}

Note: ${ }^{a}$ Consolidated adverse event category.

Abbreviations: TEAE, treatment-emergent adverse event.

\section{Data sharing statement}

Eli Lilly provides access to all individual participant data collected during the trial, after anonymization, with the exception of pharmacokinetic or genetic data. Data are available to request in a timely fashion after the indication studied has been approved in the USA and EU and after primary publication acceptance. No expiration date of data requests is currently set once they are made available. Access is provided after a proposal has been approved by an independent review committee identified for this purpose and after receipt of a signed data sharing agreement. Data and documents, including the study protocol, statistical analysis plan, clinical study report, blank or annotated case report forms, will be provided in a secure data sharing environment for up to 2 years per proposal. For details on submitting a request, see the instructions provided at www.clinicalstudydatarequest.com.

\section{Acknowledgments}

The authors acknowledge the important role of the patients, investigators, and institutions involved in this study and thank 
them for their contribution. They also thank Mary Dugan Wood for writing assistance. This work was supported by Eli Lilly and Company.

\section{Author contributions}

KM collected patient data for the study. M-HJ analyzed the study data, and all authors were involved in its interpretation. All authors contributed to data analysis, drafting and revising the article, gave final approval of the version to be published, and agree to be accountable for all aspects of the work.

\section{Disclosure}

KM reports grants and personal fees from Eli Lilly and Company during the conduct of the study; grants from Merck Sharp \& Dohme Corporation, Daiichi Sankyo Company; Shionogi \& Company, Ltd, Kyowa Hakko Kirin Company, Ltd, Gilead Sciences Inc, Sanofi S.A., Pfizer Inc, and Merck Serono, and personal fees from Chugai Pharmaceutical Company, Ltd, Taiho Oncology, Inc, Takeda Pharmaceutical Company, Ltd, Bayer AG, and Eli Lilly and Company, outside the submitted work. M-HJ is an employee of Eli Lilly and Company Ltd. RC is an employee of Eli Lilly and Company. The authors report no other conflicts of interest in this work.

\section{References}

1. Bray F, Ferlay J, Soerjomataram I, Siegel RL, Torre LA, Jemal A. Global Cancer statistics 2018: GLOBOCAN estimates of incidence and mortality worldwide for 36 cancers in 185 countries. CA Cancer J Clin. 2018;68(6):394-424.
2. Kanagavel D, Fedyanin M, Tryakin A, Tjulandin S. Second-line treatment of metastatic gastric cancer: current options and future directions. World J Gastroenterol. 2015;21(41):11621-11635.

3. Smyth EC, Verheij M, Allum W, et al. Gastric cancer: ESMO clinical practice guidelines for diagnosis, treatment and follow-up. Ann Oncol. 2016;27(suppl 5):v38-v49.

4. Ajani JA, D'Amico TA, Almhanna K, et al. Gastric cancer, version 3.2016, NCCN clinical practice guidelines in oncology. $J$ Natl Compr Canc Netw. 2016;14(10):1286-1312.

5. Japanese Gastric Cancer Association. Japanese Gastric cancer treatment guidelines 2014 (VER. 4). Gastric Cancer. 2017;20(1):1-19.

6. Fuchs CS, Tomasek J, Yong CJ, et al. Ramucirumab monotherapy for previously treated advanced gastric or gastro-oesophageal junction adenocarcinoma (regard): an international, randomised, multicentre, placebo-controlled, phase 3 trial. Lancet. 2014;383(9911):31-39.

7. Wilke H, Muro K, van Cutsem E, et al. Ramucirumab plus paclitaxel versus placebo plus paclitaxel in patients with previously treated advanced gastric or gastro-oesophageal junction adenocarcinoma (rainbow): a double-blind, randomised phase 3 trial. Lancet Oncol. 2014;15(11):1224-1235.

8. Maeda H, Kobayashi M, Sakamoto J. Evaluation and treatment of malignant ascites secondary to gastric cancer. World J Gastroenterol. 2015;21(39):10936-10947.

9. Fang N, Zhang H-Q, He B, et al. Clinicopathological characteristics and prognosis of gastric cancer with malignant ascites. Tumor Biol. 2014;35(4):3261-3268.

10. Smolle E, Taucher V, Haybaeck J. Malignant ascites in ovarian cancer and the role of targeted therapeutics. Anticancer Res. 2014;34(4):1553-1561.

11. Matsumoto H, Kawazoe A, Shimada K, et al. A retrospective study of the safety and efficacy of paclitaxel plus ramucirumab in patients with advanced or recurrent gastric cancer with ascites. BMC Cancer. 2018;18(1):120-126.

12. Masuishi T, Kadowaki S, Hirano H, et al. Impact of adding ramucirumab to paclitaxel in patients with advanced gastric cancer according to the level of ascites: a multicenter retrospective study. Ann Oncol. 2018;29(suppl_8).
Cancer Management and Research

\section{Publish your work in this journal}

Cancer Management and Research is an international, peer-reviewed open access journal focusing on cancer research and the optimal use of preventative and integrated treatment interventions to achieve improved outcomes, enhanced survival and quality of life for the cancer patient. The manuscript management system is completely online and includes

\section{Dovepress}

a very quick and fair peer-review system, which is all easy to use. Visit http://www.dovepress.com/testimonials.php to read real quotes from published authors. 